Military Technical College, Kobry El-Kobbah, Cairo, Egypt

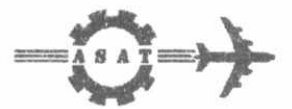

$9^{\text {th }}$ International Conference

On Aerospace Sciences \& Aviation Technology

\title{
HEAT TRANSFER ENHANCEMENT IN A RECTANGULAR DUCT WITH PERFORATED RIBS ON ONE PRINCIPAL WALL
}

\author{
A.R. EL-SHAMY*
}

\section{ABSTRACT}

Experiments were carried out to investigate the thermal performance of a rectangular duct with permeable ribs mounted on one of the principal walls. A horizontal rectangular duct with an aspect ratio (width/height) of $4: 1$ was examined. Multiple permeable ribs were attached to the bottom base surface of the channel. Constant heat flux was the boundary condition. for the ribbed wall. The perforated ribs were placed periodically and transversely to the stream wise direction. The parameters investigated in the present work are rib open-area ratio $(0,10$ and 20 percent), rib pitch to height ratio $(5,10$ and 20$)$ and Reynolds number ranged from 15,000 to 75,000 . It was found that the perforated ribs provide a substantially lower drag force in comparison with the solid type ribs and still provide enhanced heat transfer coefficient in comparison with the smooth wall duct. The results indicated that the perforated ribs with open-area ratio of $20 \%$ in a lower flow Reynolds number range provide better thermal performance under a constant power constraint. New correlations were obtained for the effects of rib pitch to height ratio, rib open-area ratio and Reynolds number on both the heat transfer and friction similarity factors.

KEYWORDS: Forced convection, heat transfer enhancement, permeable ribs, Roughened surfaces, Rectangular duct flow.

\section{NOMENCLATURE}

SI system of units was used for the whole parameters within this paper.

$\begin{array}{ll}\mathrm{C}_{\mathrm{p}} & \text { air specific heat } \\ \mathrm{D}_{\mathrm{e}} & \text { equivalent hydraulic diameter of the } \\ \mathrm{H} & \text { duct } \\ \mathrm{H} & \text { rib height }\end{array}$

\author{
Subscripts: \\ f for fluid \\ $m$ mean value \\ case of smooth duct flow
}

* Lecturer, Mech. Eng. Dept., Faculty of Eng. (Shoubra), Zagazig Univ., Cairo, Egypt. 


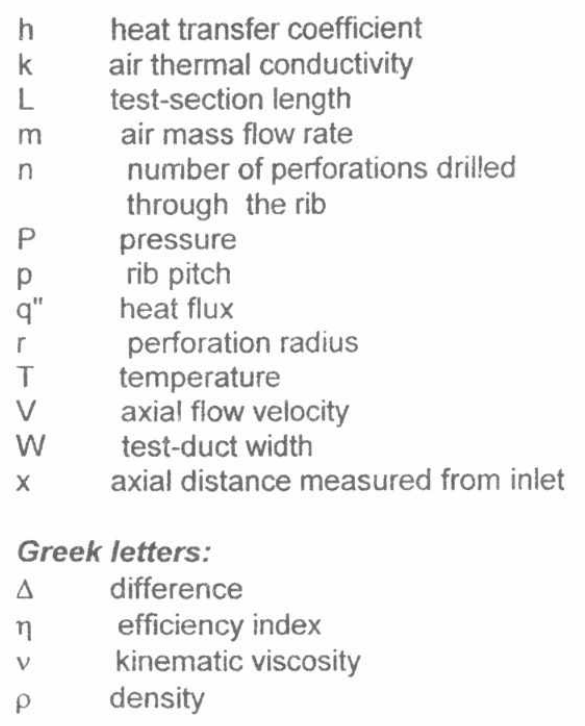

\author{
$\mathrm{R}$ ribbed region \\ w wall, surface \\ $x \quad$ local value, test segment exit \\ $x-\Delta x \quad$ test segment inlet \\ $\infty \quad$ fully developed conditions
}

Dimensionless Terms:

B open-area ratio for the perforated rib

$F \quad$ Fanning friction factor

$\mathrm{F}^{+} \quad$ Friction similarity factor

$\mathrm{H}^{+} \quad$ Heat transfer similarity factor

$\mathrm{Nu} \quad$ Nusselt number

$\mathrm{p} / \mathrm{H} \quad$ rib pitch to height ratio

Pr Prandtl number

$\operatorname{Re} \quad$ Reynolds number

$\mathrm{Re}^{+} \quad$ roughness Reynolds number

St Stanton number

\section{INTRODUCTION}

The applications of rib-type turbulators on the surfaces of high heat flux devices have attracted much attention for their significant enhancement of heat transfer. The use of solid ribs has been explored for many applications, such as heat exchangers, gas-cooled nuclear reactors and electronic cooling devices. Generally, the enhancement of heat transfer always accompanies a higher pressure drop penalty of the fluid flow. The engineers or designers have been trying to optimize the rib geometry to yield the best heat transfer performance for a given pumping power or flow rate. Several experimental investigations were carried out to study the effects of channel aspect ratio, rib angle of attack, rib spacing, rib height, rib shape and relative arrangement of ribs, [1-6]

The present work concerns the effects of perforated rib turbulators on the turbulent heat transfer and friction characteristics in a rectangular duct. Study of turbulent flow and heat transfer around the perforated ribs in a channel originated from Tanasawa et al. [7] in which the resistance heating method and thermocouple technique were used to determine the heat transfer coefficients in a channel with turbulence promoters of fence-type, perforated plate-type and slit plate-type symmetrically mounted on two opposite walls for rib open-area ratio and Reynolds number ranging from 0 to 50 percent and 13,000 to 90,000 , respectively. Results showed that surfaces with perforated plate-type turbulence promoters gave excellent performance under the same pumping power. Under the same flow conditions, Tanasawa et al. [8] subsequently compared the thermal performance of plain rectangular rib-type, perforated rib-type, and half-perforated rib-type. They concluded that half-perforated rib-type turbulence promoters with perforations on the lower half of the rib gave better performance. Ichimiya and Mitsushiro [9] 
studied the effect of rib thickness on the thermal performance and friction loss of flow in a rectangular duct with porous-type turbulence promoters arranged on one insulated wall placed opposite to the smooth heated wall for rib pitch to height ratio of 3.5 , rib open-area ratio of 87.3 percent and Reynolds number of 26,000 to 150,000 . The thermocouples measured average Nusselt number and pressure taps measured average friction factor were respectively found to be augmented to about two to four times that of the smooth duct and reduced to one fourth to two thirds of that of the solid-type turbulence promoters. Nevertheless, no conclusive trend for thickness effects was reported. Ichimiya et al. [10] further experimentally investigated the effects of a single porous-type roughness with open-area ratio of 87.3 percent on the heat transfer and friction characteristics in a parallel plate duct. The porous-type roughness was applied to the insulated wall facing the heated smooth surface. Results showed that the thermal performance under the constant pumping power constraint is better in the laminar region than in the turbulent region. Yamada and Osaka [11] conducted flow visualizations and pressure measurements to study the effects of the aspect ratio and open-area ratio of the plate on the heat transfer characteristics of the flow over a rectangular perforated plate standing on a flat wall. Only one flow velocity $(5 \mathrm{~m} / \mathrm{s})$ was tested. They found that the critical openarea ratios for the presence of a recirculation behind the plate were between 32.5 and 48.5 percent. Hwang and Liou [12] carried out experiments to study the turbulent heat transfer and friction in a low-aspect ratio rectangular channel in which two opposite walls were roughened by perforated ribs. The perforated ribs were arranged in a staggered manner. Effects of perforated rib open-area ratio, rib pitch to height ratio, rib height to channel hydraulic diameter ratio, rib alignment (staggered and symmetric) and Reynolds number were examined. It was found that approximately the same heat transfer enhancement and pressure drop penalty were obtained between symmetric and staggered rib arrangements. Results also show that ribs with an open area ratio of 44 percent yields the best heat transfer enhancement under the same pumping power constraint. Hwang [13] performed an experimental investigation to examine the heat transfer and friction characteristics in a rectangular duct with one wall roughened by slit and solid ribs. The effects of rib void fraction and flow Reynolds number were examined. The rib height to duct hydraulic diameter and pitch to height ratios were fixed at 0.167 and 10 respectively. Two contributive factors of heat transfer promotion, namely, the fin effect and the enhanced turbulence effect, had been isolated. The results also showed that slit ribs with larger void fractions in a lower flow Reynolds number range provide better thermal performance under a constant friction power constraint. Liou et al. [14] focused on the flow characteristics in a channel containing perforated ribs. The fixed parameters were rib height to duct hydraulic diameter ratio of 0.106 , rib width to height ratio of 0.76 , rib pitch to height ratio of 10 and Reynolds number of 20,000, while the main parameter investigated was the rib open-area ratio with values of $0,10,22,38$ and 44 percent. Two critical ranges of rib openuseful referend three characteristic flow regimes were identified, which provides useful references of practical tests of computational models. The results also showed that the secondary flow mean velocity components were found to be one to two orders of magnitude smaller than the bulk mean velocity. Recently, the thermal performance of solid and perforated rectangular blocks attached on a flat surface in a rectangular duct were experimentally investigated by Sara et al. [15] for varying 
flow and geometrical conditions. It was found that the solid blocks generated a net energy loss despite significantly enhanced heat transfer due to the increased heat transfer surface area. When the blocks were perforated, the loss in the net energy was recovered and depending on the geometrical and flow conditions, a net gain in energy, up to $20 \%$, was achieved. Also, it was found that for both the solid and the perforated blocks, the increase in Reynolds number leads to a decrease in the performance.

The objectives of the present study are:

- to investigate the heat transfer and friction characteristics in a rectangular channel ribbed with multiple perforated ribs on one of the principle walls.

- to establish the effects of rib open-area ratio, rib pitch to height ratio and Reynolds number on the thermal performance.

- to obtain new correlations for both the heat transfer and friction similarity factors for the present rib configurations.

\section{EXPERIMENTAL APPARATUS}

The experimental apparatus employed in this investigation is a horizontal low-speed wind tunnel operated in a suction mode, as shown schematically in Fig. (1-a). It consists mainly of a blower assembly, air passage, test-section, and measuring instruments. A centrifugal type air blower of $160 \mathrm{~mm}$ inlet section diameter driven by an $\mathrm{AC}$ motor of $3 \mathrm{hp}$ capacity, is used to supply the system with air at the required flow rate. The airflow rate is controlled at the outlet of the air blower via a variable area outlet gate. A transition piece from a circular section of diameter $160 \mathrm{~mm}$ to a rectangular one with $160 \times 40 \mathrm{~mm}$ is used to connect the air blower to the unheated exit duct of the test section. The test section is $1200 \mathrm{~mm}$ long and has a rectangular cross section of $160 \mathrm{~mm}$ by $40 \mathrm{~mm}$ with an aspect ratio of $4: 1$, as shown in Fig.(1-b). The corresponding hydraulic diameter of the test section is $64 \mathrm{~mm}$. The lower horizontal wall of the test section is heated and the remaining three duct walls are thermally insulated. Upstream of the test section is an unheated entrance section made of plexiglass with the same cross section and length as the test section. This unheated section provides a hydrodynamically fully developed condition at the entrance of the heated test section. The heat transfer surface is made of $6 \mathrm{~mm}$-thick aluminum plate. Rectangular brass ribs are used in this study with dimensions of 160 $\mathrm{mm}$ in length, $5 \mathrm{~mm}$ in width and $10 \mathrm{~mm}$ in height. The surfaces of the aluminum plate and brass ribs are highly polished to minimize emissivity, hence radiative losses. The perforated ribs are attached to the bottom wall of the test duct by a thin layer of thermal glue and they are fixed at downstream distance of 10 hydraulic diameter from the start of heating, as shown in Fig.(1-c), to assure that thermally fully developed flow is established. The perforated ribs are placed periodically and transversely to the stream wise direction. The present investigated rib pitch to height ratios are 5, 10, 20 and the rib open-area ratios are 0,10,20 percent. Two main heater segments are used to heat the test section, one for the smooth region and the other for the ribbed one. The heater segments are formed by winding a Nickelchromium wires uniformly around a thin mica sheet and sandwiched between another two mica sheets and then inserted between the aluminum plate and a $6-\mathrm{mm}$ 
thick asbestos board. Another similar heater, which worked as a guard heater, is used to minimize the heat loss from the backside of the heated plate. The whole system is tightly fastened with through bolts to insure good contact. Details of the test duct cross section are shown in Fig.(1-b). Three pressure taps along the test duct are used for the static pressure drop measurements. The heating surface temperatures were measured at different test positions with calibrated copperconstantan thermocouples distributed along the length and across the span of the aluminum plate with higher concentration at the ribbed region as shown in Fig.(1-d). The used thermocouples were made from wires of $0.3 \mathrm{~mm}$ diameter and connected to a digital thermometer sensitive to $0.1{ }^{\circ} \mathrm{C}$. The bulk mean air temperature at test section inlet and exit was measured with thermocouples, which could be traversed vertically. Also, the airflow rate was measured by a calibrated orifice-meter connected to a digital micromanometer accurate to $1 \mathrm{~Pa}$. This digital micromanometer is used also to measure the pressure distributions along the test section. Electric power is supplied via voltage regulators to provide uniform heat fluxes for the smooth and ribbed regions. Also, a digital multimeter is used to measure the electric resistances, currents and voltages of the main and guard heaters, respectively. The steady state was assumed to be established if the wall and air flow temperatures changed within $0.1^{\circ} \mathrm{C}$ during 15 minutes. Then the data of electric power input, the temperature distributions on the heating surface, inlet and exit air flow temperatures and pressure drop were recorded.

\section{EXPERIMENTAL PROCEDURE AND METHOD OF CALCULATIONS}

The present investigated perforated ribs having circular holes with $1.5 \mathrm{~mm}$ diameter machined into brass ribs $(5 \mathrm{~mm}$ width). Three rows of perforations are in-line alignment. The open-area ratio of the perforated rib is defined as:

$$
B=\frac{n \pi r^{2}}{W \cdot H}
$$

Where $n$ is the number of perforations distributed on the rib, $r$, the radius of the perforation, $W$, the channel width (rib length), and $H$, the rib height. The rib openarea ratios investigated are 0,10 , and 20 percent.

The test duct is divided into 26 axial segments with unequal lengths concentrated on the ribbed region (the downstream half of the test duct). The temperature readings were recorded after achieving steady state. The power input to the heaters was computed from the measurements of the voltage and resistance of the main heater segments and then the heat flux applied to each segment was obtained. During the tests, it was found that the ribbed region heat transfer capability was higher than that for the smooth one. In order to reduce the conduction between the smooth and rough walls, the heat input to the rough wall was controlled at about 1.5 to 2.0 of that differen smooth wall. This was accomplished by maintaining the temperature difference around the interface of the two regions not exceeds $0.5^{\circ} \mathrm{C}$. The heat lost parameters. Also parameters. Also, the average heat flux to the test section was obtained by test section. The average increase in bulk temperature may be found by measuring 
the bulk temperatures at the entrance and exit of the test section. Since the values of the mass flow rate and the specific heat of air are known quantities, the heat flux may be calculated. This measurement was used just as a check of the heat flux measurement by the power input to the electrical heater. The heat balance was found to be valid within $\pm 4 \%$.

Knowledge of the average heat flux q" and the local surface temperatures of the test duct segments allowed for the computation of the local heat transfer coefficient $h_{x}$ from the defining equation:

$$
\mathrm{h}_{\mathrm{x}}=\frac{\mathrm{q}^{\prime \prime}}{\overline{\mathrm{T}}_{\mathrm{w}, \mathrm{x}}-\overline{\mathrm{T}}_{t, \mathrm{x}}}
$$

where, $q^{n}$ is the heat flux

$\overline{\mathrm{T}}_{w . x}$ is the mean surface temperature of the test segment

$\bar{T}_{f, x}$ is the flow mean temperature at the duct segment and it is calcuiated by averaging the segment inlet and exit temperatures: $\bar{T}_{f, x}=\left(T_{f, x+} T_{f, x-\Delta x}\right) / 2$

where, $T_{f, x-\Delta x}$ and $T_{f, x}$ are the flow inlet and exit temperatures which are functionally related by successive heat balance for the duct segments as:

$$
T_{f, x}=T_{f, x-1 x}+\frac{q^{\prime \prime}(W \cdot \Delta x)}{\dot{m} c_{p}}
$$

and, $\Delta x$ is the test duct segment length. Also, the value of the measured inlet flow temperature is assigned to $T_{f, x-\Delta x}$ for the first test segment.

The local Nusselt number based on the equivalent hydraulic diameter $\left(D_{e}\right)$ was evaluated as:

$$
N u_{x}=\frac{h_{x} D_{e}}{k_{f}}=\frac{q^{\prime \prime} D_{e}}{k_{f}\left(\bar{T}_{w, x}-\bar{T}_{f, x}\right)}
$$

The fully developed Nusselt number $\left(\mathrm{Nu}_{\infty}\right)$ for the thermally fully developed region was evaluated by averaging the local values. Also, the flow Reynolds number based on the equivalent hydraulic diameter $\left(D_{e}\right)$ was calculated by $R e=\frac{V D_{e}}{v}$, where, $V$ is the airflow mean velocity calculated from the measured mass flow rate. The thermophysical air properties are based on the mean film ternperature. The Fanning friction factor $(F)$ was calculated in terms of the flow frictional pressure drop along the ribbed region of the test section as:

$$
F=\left(\frac{\Delta P_{R}}{2 \rho V^{2}}\right) \frac{D_{e}}{L_{R}}
$$




\section{RESULTS AND DISCUSSION}

Prior to the solid and perforated-ribbed duct experiments, fully developed Nusselt numbers and friction factors are calculated for a smooth duct and compared with the results given in the literature, as shown in Figs. $(2,4)$. The correlations selected for comparison are the Dittus-Boelter equation cited in [16] for heat transfer and the Blasius equation cited in [17] for friction. These equations provide good representations of the present results for a fully developed flow in smooth ducts. This gives confidence that the present test procedure is accurate.

The present heat transfer results for smooth duct flow were correlated and the following correlation was obtained:

$$
\mathrm{Nu}_{0}=0.02177 \mathrm{Re}^{0.8}
$$

This correlation is valid within $\pm 15 \%$ maximum deviation with the present experimental data within a range of Reynolds number from 15000 to 75000 Also, the present values of the friction factors for smooth duct flow were correlated in terms of Reynolds number and the following correlation was obtained:

$$
F_{\mathrm{o}}=0.0567 \mathrm{Re}^{.0 .2}
$$

This correlation is valid within $\pm 10 \%$ maximum deviation with the present experimental data within the investigated range of Reynolds number.

Figure (2) shows the variations of the fully developed Nusselt number with Reynolds number at different open-area and pitch to height ratios. As a result of the flow reattachment and impingement on the ribbed-wall, expected higher values for geometry wither were found. The Nusselt number values for the perforated rib geometry with open-area ratio of 10 percent are found to be almost the same as those for the solid-type rib geometry. Higher Nusselt number values were observed for the rib walled duct with open-area ratio of 20 percent. The results of similar duct blockage in the previous work are displayed in Fig.(2-b) for comparison. These results from Liou and Hwang [3] are for two-opposite solid-rib walled duct of colio is nearly identical with the present one solid-rib walled duct with $H / D_{e}=0.156$. The comparison shows a satisfactory Reynolds number these two ducts. The variation of the Stanton number with Reynolds number at different open-area and pitch to height ratios are shown in the ribbed-duct over that of the smooth duct.

Figure (4) illustrates the combined effects of the rib pitch to height ratio, rib openarea ratio and flow Reynolds number on the Fannirig friction factor for the solid and much higher than its solid-ribbed dhan its counterpart for the smooth duct, but lower than that for the ratio and Reynolds number, whereastor decreases with increasing the rib open-area pitch to height ratio. walled duct are presented in Fig of Liou and Hwang [3] for two-opposite solid-rib Following the rougented in Fig.(4-b) for comparison with the present results. wall similarity laws were employed to correlate the friction and heat transfer data for 
fully developed turbulent flow in the present rectangular duct with one wall roughened by solid and perforated ribs. The present friction similarity law could be considered a combination of smooth duct friction similarity law plus a correction term due to rough surface effect suggested by Dippery and Sabersky [18]. The friction and heat transfer similarity factors for the present roughness geometries are calculated utilizing the present data, respectively, as follows:

$$
\begin{aligned}
& F^{+}=\sqrt{\frac{2}{F}}+2.5 \ln \left(\frac{2 H}{D_{e}}\right)+3.75 \\
& H^{+}=\left(\frac{F}{2 S t}-1\right) / \sqrt{\frac{F}{2}}+F^{+}
\end{aligned}
$$

Also, the roughness Reynolds number is calculated as:

$$
\operatorname{Re}^{+}=\operatorname{Re}\left(\frac{H}{D_{e}}\right) \sqrt{\frac{F}{2}}
$$

Figure (5) shows the variation of the friction similarity factor with the roughness Reynolds number at different open-area and pitch to height ratios. The present results indicate that the friction similarity factor depends on the rib open-area ratio and is almost independent on each of the pitch to height ratio and the roughness Reynolds number for all rib configurations studied. This indicates that the present study is a fully rough regime. Also, the results of Liou and Hwang [3] for two opposite solid-rib walled duct with nearly the same blockage ratio are presented in Fig.(5-b) for comparison with the present results and good agreement was observed. The following correlation was obtained for the friction similarity factor:

$$
\mathrm{F}^{+}=6.2(1-\mathrm{B})^{-0.774}
$$

This correlation is valid within $\pm 3 \%$ maximum deviation with the present experimental data within the investigated range of Reynolds number from 15,000 to 75,000 , for pitch to height ratios from 5 to 20 and for open-area ratios ranging from
0 and $20 \%$.

The present data of the friction similarity factor were introduced in calculating the heat transfer similarity factor. The effects of rib open-area and pitch to height ratios on the heat transfer similarity factor are shown in Fig.(6). Generally, the heat transfer similarity factor increases with increasing the roughness Reynolds number for all studied rib configurations. The results of $\mathrm{Han}$ [1] for similar solid rib-walled duct are displayed in Fig.(6-b) for comparison with the present results. The present heat transfer similarity factor results were correlated and the following correlation was
obtained:

$$
H^{+}=3.7\left(\operatorname{Re}^{+}\right)^{0.28}(1-B)^{0.277}
$$


This correlation is valid within $\pm 5 \%$ maximum deviation with the present experimental data for the investigated ranges of the studied parameters.

One of the performance evaluation criteria was chosen to compare the enhanced thermal performance of a ribbed duct to that of a smooth-walled duct under constant power constraint as suggested by Han [1]. The efficiency index, which is defined by the ratio between the Stanton number enhancement ratio $\left(\mathrm{St}_{\mathrm{S}} \mathrm{St}_{\mathrm{o}}\right)$ to the friction factor ratio $\left(F / F_{0}\right), \eta=\frac{S t / S_{0}}{F / F_{o}} \quad$ was calculated and plotted against the roughness Reynolds number at different rib configurations as shown in Fig.(7). It can be seen that, higher values of the efficiency index at lower roughness Reynolds number were observed and then the value of the efficiency index decreases monotonically at higher values of roughness Reynolds number. This behavior was mainly caused by the friction factor for the smooth duct, which is a function of Reynolds number. Also, it is clear that the perforated rib walled-duct has a higher performance than the solid rib walled-duct, especially for the larger open-area ratio.

\section{CONCLUDING REMARKS}

The mechanisms of heat transfer augmentation have been studied experimentally in a rectangular duct with one wall roughened by perforated ribs. The effects of the rib pitch to height ratio, the rib open-area ratio and Reynolds number have been examined. The main findings based on the present measurements are as follows:

1- Generally, changing the rib open-area ratio has a marked effect on the friction factor and heat transfer coefficients.

2- The fully developed Nusselt number values for the perforated rib geometry with open-area ratio of 10 percent are found to be almost the same as those for the solid-type rib geometry, whereas higher Nusselt number values were observed for the rib walled duct with open-area ratio of 20 percent.

3- The friction factor for the perforated ribbed duct is lower than that for the solid ribbed duct, and decreases with increasing rib open-area ratio.

4- The friction similarity factor depends on the rib open-area ratio and is almost independent on each of the pitch to height ratio and the roughness Reynolds number for all rib configurations studied. This indicates that the present study is a
fully rough regime.

5- Higher values of the efficiency index at lower roughness Reynolds number were observed and then the value of the efficiency index decreases monotonically at higher values of roughness Reynolds number.

6- A performance comparison reveals that the perforated ribs with open-area ratio of 20 percent in a lower flow Reynolds number range provide better thermal performance under a constant power constraint

7- Empirical correlations were obtained for the effects of rib pitch to height ratio, rib open-area ratio, and Reynolds number on both the heat transfer and friction such as factors. These correlations can be used in the design of related devices such as heat exchangers, electric cooling packages and turbine blade cooling
channels. 


\section{REFERENCES}

[1] Han, J. C., "Heat Transfer and Friction Characteristics in Rectangular Channels with Rib Turbulators", ASME Journal of Heat Transfer, Vol. 110, pp. 321-328, (1988).

[2] Han, J. C., Park, J. S., and Lei, C. K., "Heat Transfer Enhancement in Channels with Turbulence Promoters", ASME Journal of Heat Transfer, Vol. 107, pp. 628635, (1985).

[3] Liou, T. M., and Hwang, J. J., "Turbulent Heat Transfer Augmentation and Friction in Periodic Fully Developed Channel Flows", ASME Journal of Heat Transfer, Vol. 114, pp. 56-64, (1992a).

[4] Liou, T. M., and Hwang, J. J., "Developing Heat Transfer and Friction in a Rectangular Ribbed Duct with Flow Separation at Inlet", ASME Journal of Heat Transfer, Vol. 114, pp. 565-673, (1992b).

[5] Liou, T. M., and Hwang, J. J., "Effects of Ridge Shapes on Turbulent Heat Transfer and Friction in a Rectangular Channel", Int. J. Heat Mass Transfer, Vol. 36, pp. 931-940, (1993).

[6] Lau, S. C., McMillin, R. D., and Han, J. C., "Turbulent Heat Transfer and Friction in a Square Channel with Discrete Rib Turbulators", ASME Journal of Turbomachinery, Vol. 113, pp. 360-366, (1991).

[7] Tanasawa, T., Nishio, S., Takano, K., and Tado, M., "Enhancement Forced Convection Heat Transfer in a Rectangular Channel Using Turbulence Promoters", Proceedings ASME-JSME Thermal Engineering Joint Conference, pp. 395-402, (1983).

[8] Tanasawa, T., Nishio, S., and Takano, K., "High Performance Surface for Forced Convection Heat Transfer Using Novel Turbulence Promoters", ASME paper 84-HT-69, (1984).

[9] Ichimiya, K., and Mitsushiro, K., "Enhancement of the Heat Transfer of Wide Temperature Range in a Narrow Passage", Proceedings of Experimental Heat Transfer, Fluid Mechanics, and Thermodynamics, pp. 659-664, Dubrovnik, Yugoslavia, (1988).

[10] Ichimiya, K., Katayama, M., Miyazawa, T., and Kondoh, H., "Experimental Study on Effects of a Single Porous-Type Roughness Element in a Parallel-Plate Duct", Experimental Heat Transfer, Vol. 4, pp. 319-330,(1991).

[11] Yamada, H., and Osaka, H., "Flow Around a Permeable Rectangular Plate Standing Vertically on the Flat Wall, $2^{\text {nd }}$ Report, Effects of the Aspect and Open Area Ratios", Trans. JSME, Vol. 56, No. 546, pp. 120-128, (1992).

[12] Hwang, J. J., and Liou, T. M., "Heat Transfer and Friction in a Low-Aspect-Ratio Rectangular Channel With Staggered Perforated Ribs on Two Opposite Walls", ASME Journal of Heat Transfer, Vol. 117, pp. 843-850, (1995).

[13] Hwang, J. J., "Heat Transfer-Friction Characteristic Comparison in Rectangular Ducts With Slit and Solid Ribs Mounted on One Wall", ASME Journal of Heat Transfer, Vol. 120, pp. 709-716, (1998).

[14] Liou, T. M., Kao, C. W., Chen, S. H., "Flow Field Investigation of the Effect of Rib Open Area Ratio in a Rectangular Duct", ASME Journal of Heat Transfer, Vol. 120, pp. 504-512, (1998). 
[15] Sara, O. N., Pekdemir, T., Yapici, S., and Ersahan, H., "Thermal Performance Analysis for Solid and Perforated Blocks Attached on a Flat Surface in Duct Flow", Energy Conversion and Management, Vol. 41, No. 10, pp. 1019-1028, (2000).

[16] Incropera, F.P. and DeWitt, D.P., "Fundamentals of Heat and Mass Transfer", $3^{\text {rd }}$ ed., John Wiley and Sons, New York, (1990).

[17] Schlichting, H.,"Boundary Layer Theory", $7^{\text {th }}$ ed., McGraw-Hill, New York, (1979)

[18] Dippery, D. F., and Sabersky, R. H., "Heat and Momentum Transfer in Smooth and Rough Tubes", Int. J. Heat Mass Transfer, Vol. 6, pp. 329-353, (1963). 


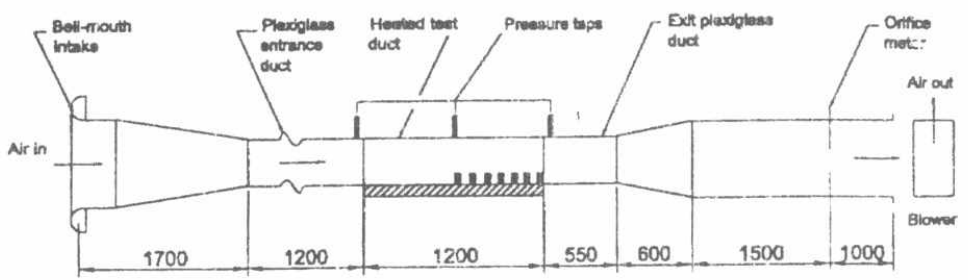

(a) Schematic diagram of the experinental apparatus

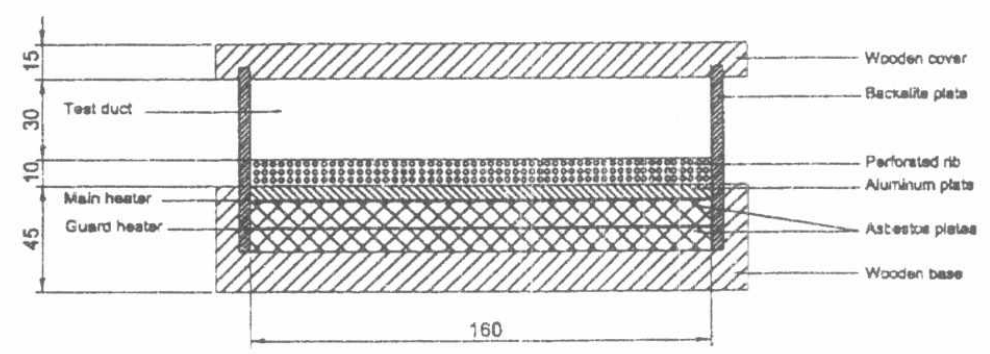

(b) Cross sectional side view of the test duct

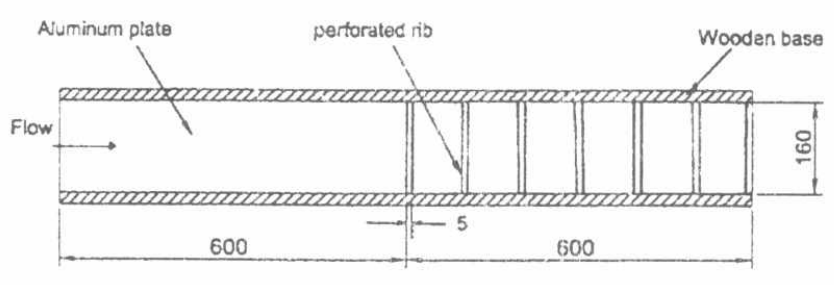

(c) Cross sectional plan of the test duct

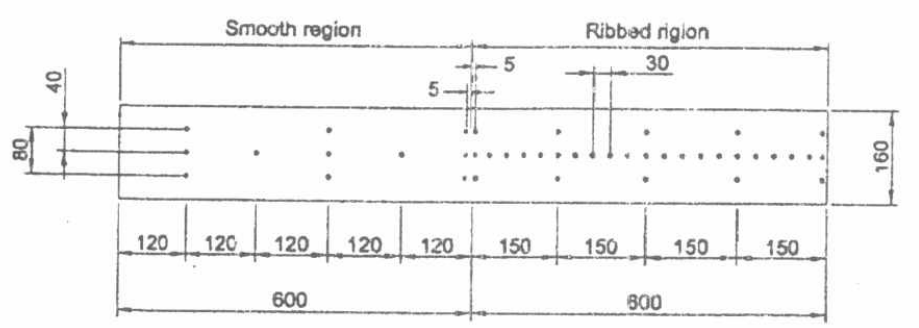

(d) Thermocouples distributions

Dims in mens

Fig.(1): The Experimental apparatus 


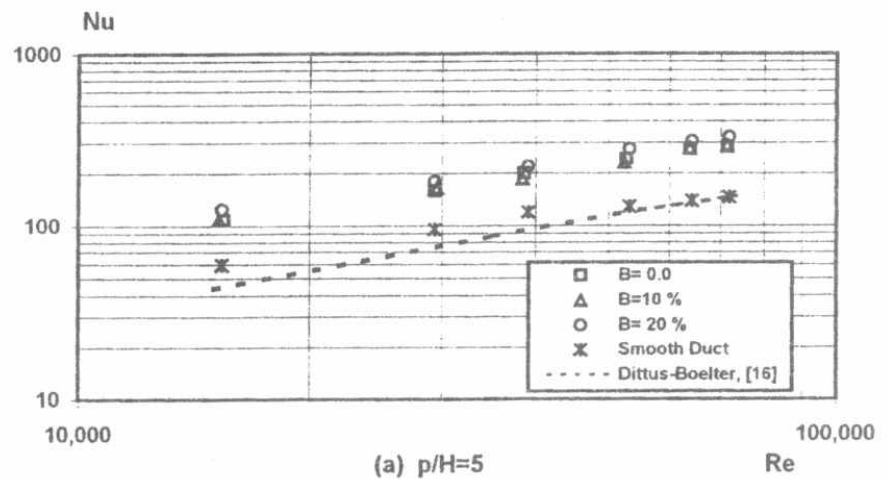

$\mathrm{Nu}$

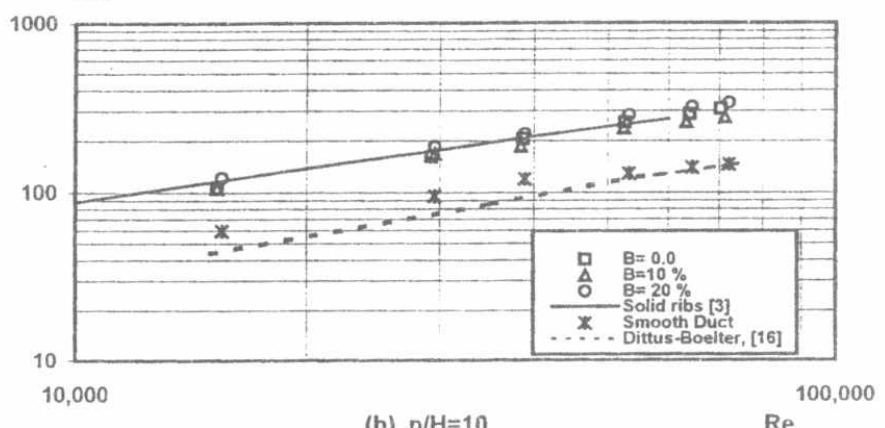

(b) $\mathrm{p} / \mathrm{H}=10$

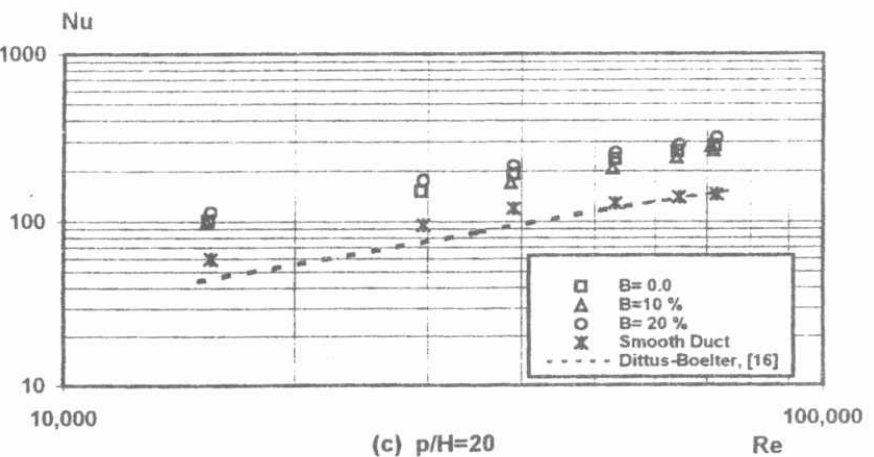

Fig.(2): Fullydeveloped Nusselt number versus Reynolds number at different open-area and $\mathrm{p} / \mathrm{H}$ ratios 


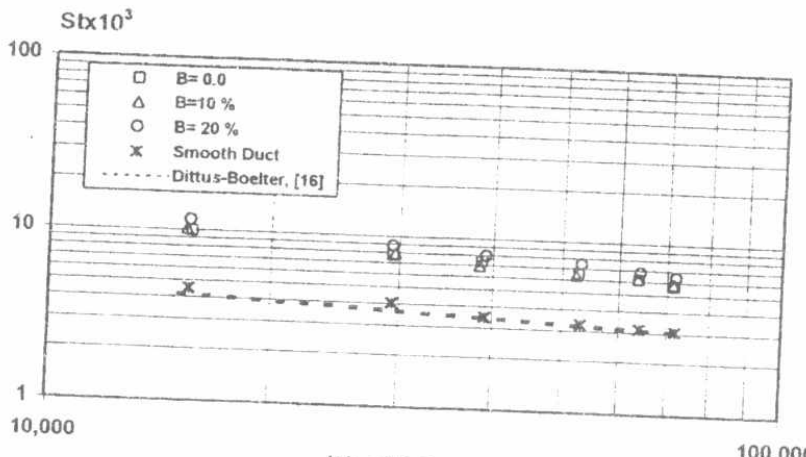

(a) $\mathrm{p} / \mathrm{H}=5$

$\mathrm{Re}$

St $\times 10^{3}$

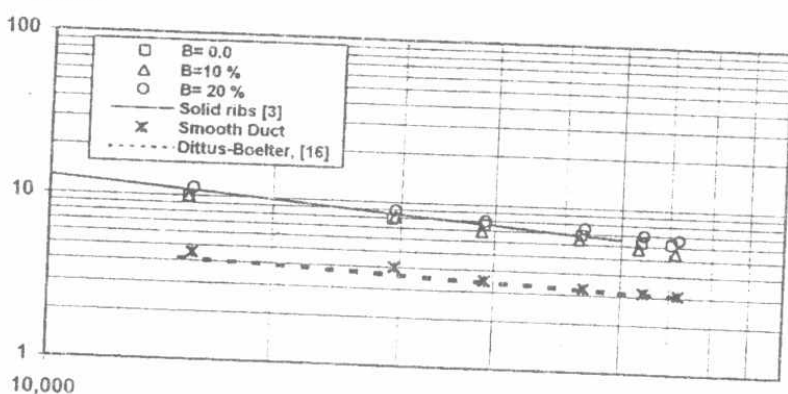

(b) $\mathrm{p} / \mathrm{H}=10$

Stx $\times 10^{3}$

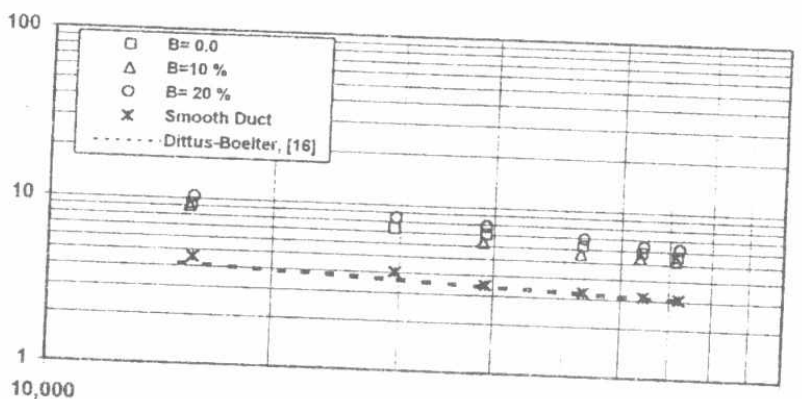

(c) $\mathrm{p} / \mathrm{H}=20 \quad \mathrm{Re}^{100,000}$

Fig.(3): Stanton number versus Reynolds number at different open-area and $\mathrm{p} / \mathrm{H}$ ratios 


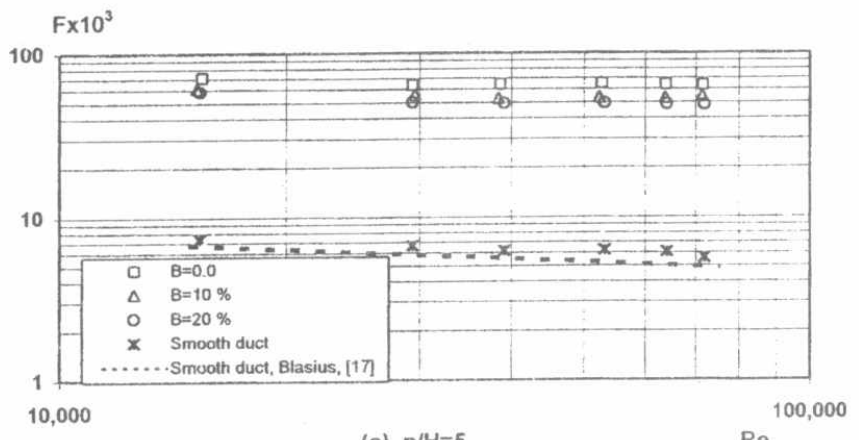

(a) $\mathrm{p} / \mathrm{H}=5$

$\mathrm{Re}$

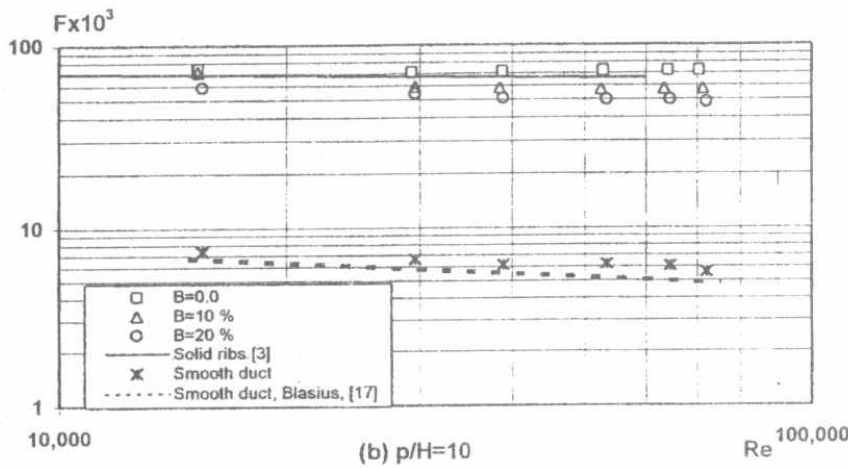

$\mathrm{F} \times 10^{3}$

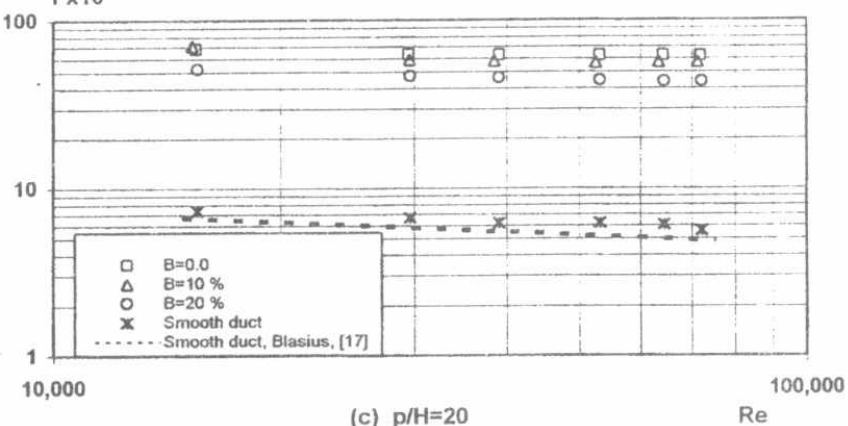

Fig.(4): Friction factor versus Reynolds number at different open-area and $\mathrm{p} / \mathrm{H}$ ratios 

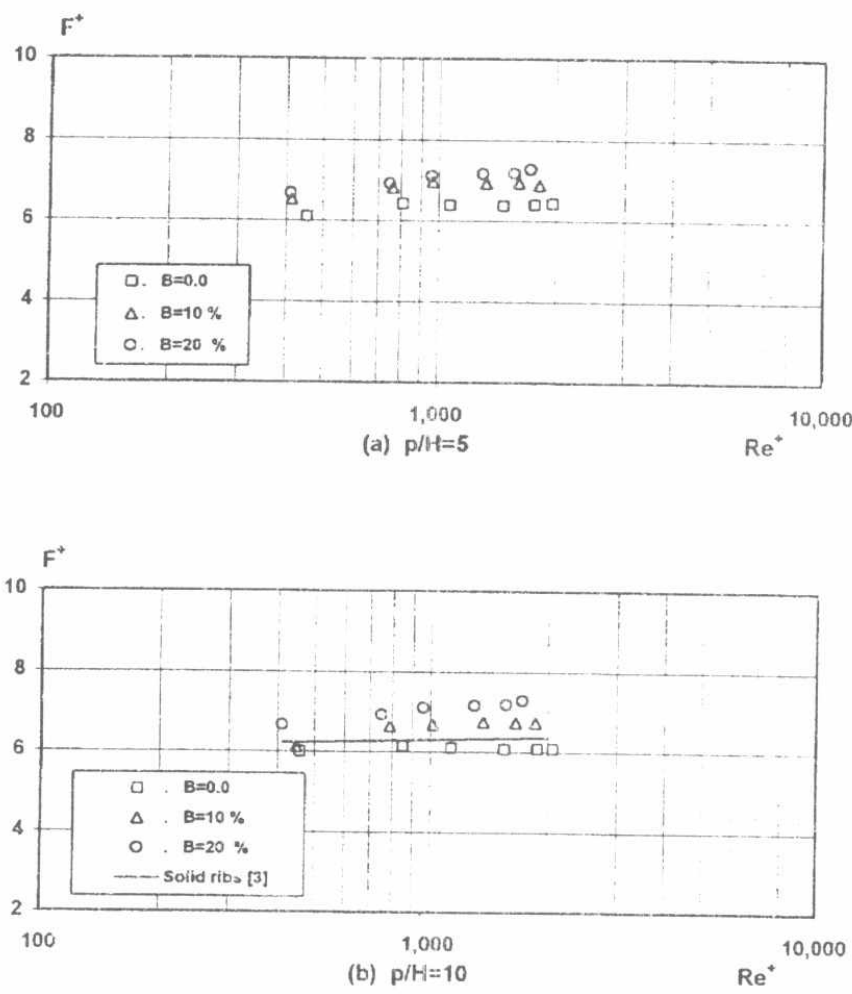

$\mathrm{F}^{*}$

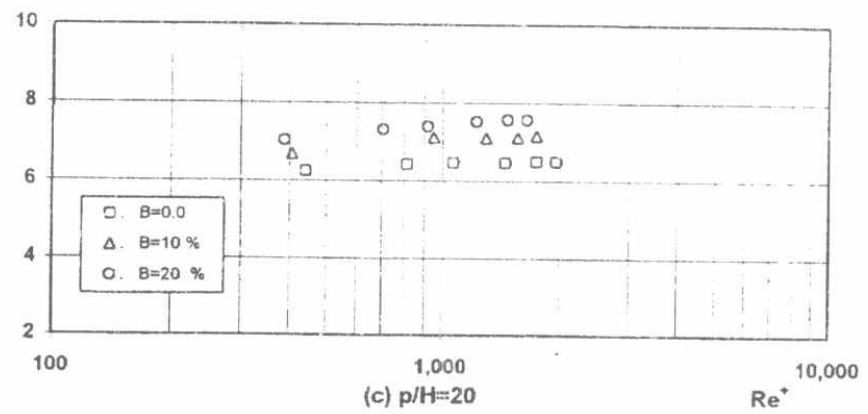

Fig.(5): Friction similarity factor versus roughness Reynolds number at different open-area and $\mathrm{p} / \mathrm{H}$ ratios 


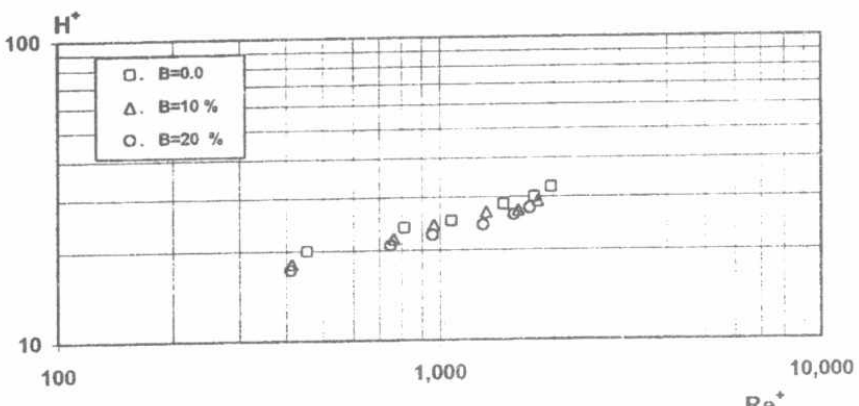

(a) $\mathrm{p} / \mathrm{H}=5$

$\mathrm{H}^{+}$

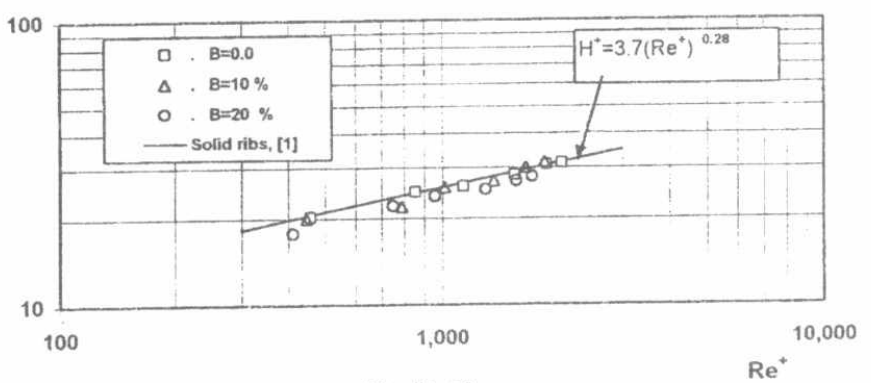

(b) $\mathrm{p} / \mathrm{H}=10$

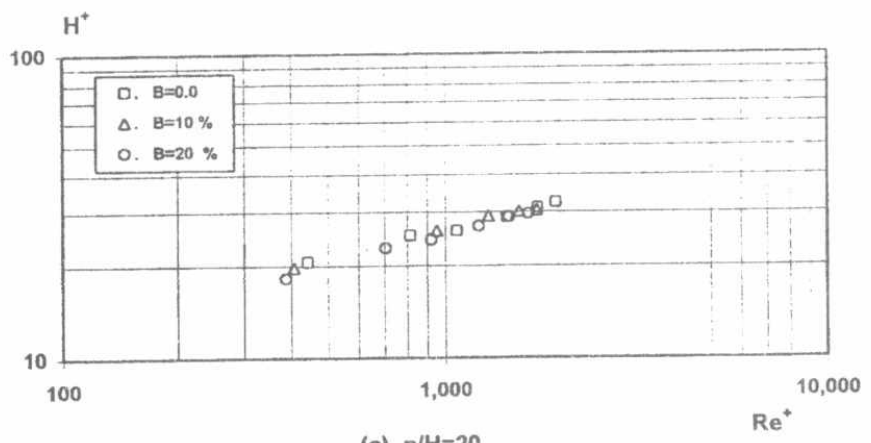

(c) $\mathrm{p} / \mathrm{H}=20$

Fig.(6): Heat transfer similarity factor versus roughness Reynolds number at different open-area and $\mathrm{p} / \mathrm{H}$ ratios 

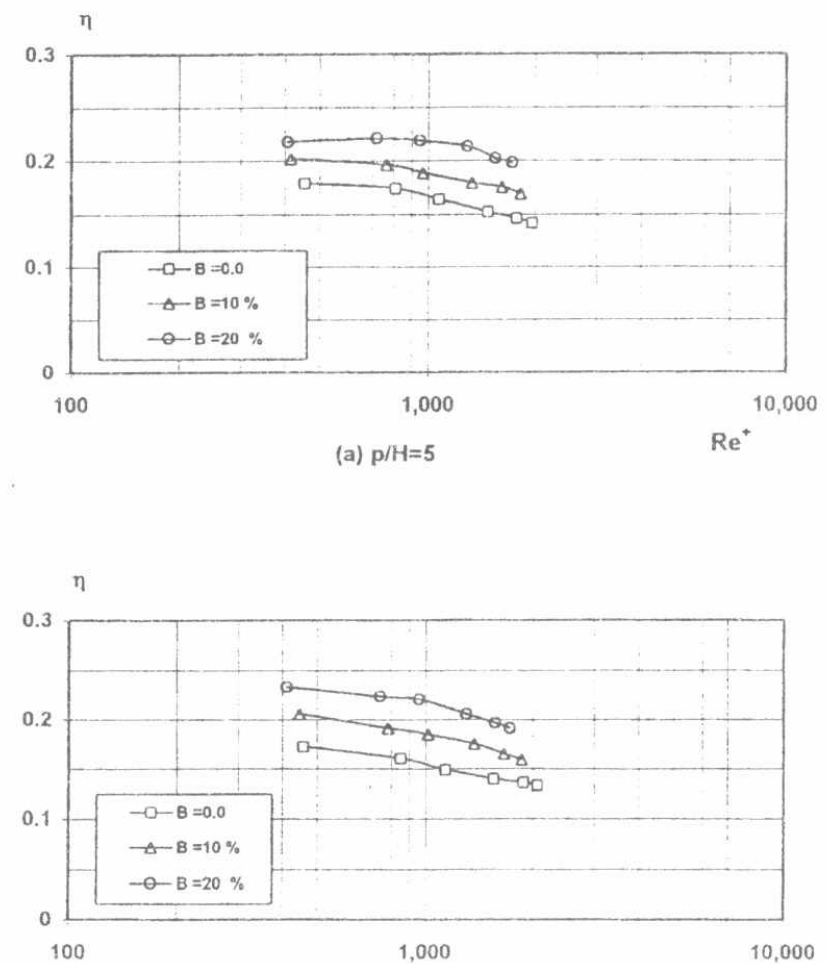

(b) $\mathrm{p} / \mathrm{H}=10$

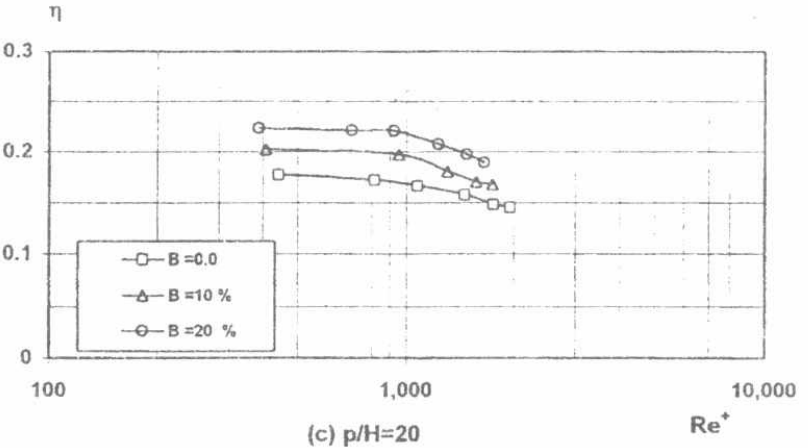

Fig.(7): Roughness efficincy index versus roughness Reynolds number for different rib-configurations 